\title{
Artefatos escolares e saberes em apresentação: estudos de cultura material
}

\author{
Gizele de Souza* \\ Vera Lucia Gaspar da Silva**
}

“... o passado não é um lugar estável, e sim precário, permanentemente alterado pelo futuro, e... portanto nada do que já ocorreu é irreversivel".

Javier Cercas $^{1}$

Através das palavras extraídas da refinada literatura de Javier Cercas, expressamos a inquietação que nos move no sentido de buscar e fortalecer formas de ler e compreender a oficialização ${ }^{2}$ da escola e do aluno e sua difusão. Num leque de possibilidades elegemos algumas formas, como diz Heloisa Rocha $(2019)^{3}$, de "interrogar o passado educacional por meio do exame dos artefatos e dos modos de fabricação inventados por diferentes sujeitos e grupos, para responder às demandas da escolarização", evidenciando também "dimensões envolvidas na cadeia de produção e circulação dos artefatos escolares". Isto significa dizer que nos ocupamos particularmente da dimensão material da escolarização da infância em diferentes lugares, de formas de organização e provimento material da escola primária e de modos de circulação das ideias que conformam (no sentido mesmo de dar forma) esta materialidade. Nesta esteira, identificar discursos que advogam um desenho material para a escola,

* Universidade Federal do Paraná. Setor de Educação. Programa de Pós-Graduação em Educação. Núcleo de Estudos e Pesquisas em Infância e Educação Infantil (NEPIE). Curitiba, Paraná, Brasil. E-mail: gizelesouza@ufpr.br. http://orcid.org/0000-0002-6487-4300.

** Universidade do Estado de Santa Catarina. Programa de Pós-Graduação em Educação. Grupo de Pesquisa Objetos da Escola. Florianópolis, Santa Catarina, Brasil. E-mail: vera.gaspar. udesc@gmail.com. https://orcid.org/0000-0003-2957-5708.

1 A velocidade da Luz. Javier Cercas, 2018, p. 202.

2 Inspiramo-nos aqui em reflexões de Carlos Manique da Silva inscritas no artigo do autor que compõe este dossiê.

3 Em texto que compõe esse dossiê. 
formas de operacionalização e modos de uso ajudam a compor um cenário que explicita sentidos que esta materialidade porta.

Como já tem sido indicado na literatura da área, ao assumir a tarefa de escolarização da infância, na esteira dos processos de obrigatoriedade escolar, os Estados, como importantes compradores, sustentam o surgimento e expansão de segmentos da indústria emergente, particularmente na segunda metade do século XIX e décadas iniciais do século seguinte. Vemos aqui espaços de divulgação e difusão de modelos - com particular destaque para as Exposições Universais, os Manuais Pedagógicos e os Museus Pedagógicos -, a disputa pela afirmação de modelos a serem consagrados como mais modernos e adequados, bem como desafios e embates que se dão seja nas relações comerciais, seja nas instituições escolares, para alcançar o ideal referendado nos discursos, atender as prescrições inscritas na legislação, bem como viabilizar as atividades pedagógicas. Assim, como apontam as autoras Patricia Costa e Ana Chrystina Mignot (2019), discutir o aparelhamento da educação, formas de fazê-lo e aspectos ali envolvidos ajuda a desvelar tensões entre distintos projetos educativos e a compreender acerca de diferentes propósitos ali inscritos.

Como desdobramento importante deste processo temos a organização de uma legislação e de dispositivos burocráticos estatais que passam a se ocupar do detalhamento tanto da composição material da escola, como dos artefatos que a compõem, de modo a orientar a indústria, a contratação de serviços, a elaboração de alguns artefatos e seus usos ${ }^{4}$. $\mathrm{Na}$ mesma medida o mercado precisará encontrar formas de se adaptar às exigências num jogo nada desprezível que envolve estratégias políticas e recursos técnicos. Esta indústria que se articula também vai demandar fornecimento de matéria prima, o que significa reorganização de formas de produzi-la e fornecê-la em maior escala que envolve, por exemplo, extração e beneficiamento de madeira, instalação de fábricas com capacidade para produzir peças de ferro, instalação e expansão da indústria especializada em artefatos de papel, para citar apenas alguns aspectos. Esta indústria incorporará tanto um conjunto de profissionais não especializados, mas capazes de operar maquinários, como também trabalhadores com grande experiência em trabalhos em madeira, ilustradores e engenheiros. Pari e passu, constituiu-se uma rede de comerciantes e fornecedores que se combina entre a fabricação artesanal e uma potente indústria ${ }^{5}$.

Aspecto não menos importante e que vem recebendo a atenção envol-

4 Este aspecto é explorado por Anna Ascenzi no artigo "As fábricas de papel Pigna e a produção industrial de cadernos escolares (Itália, entre os séculos XIX e XX)", que integra este dossiê.

5 No artigo "Negócios Combinados: modos de prover a escola pública primária (em fins do século XIX e início do XX), que compõe este dossiê, ocupamo-nos deste tema com maior atenção". 
ve a circulação de artefatos que, nas mãos dos alunos, carregam o percurso entre escola e casa numa comunicação que tem neste artefato o motor que produz o movimento e é tradutor de sentidos. Anna Ascenzi, em artigo que compõe este dossiê, aprofunda tal questão, discutindo, por exemplo, estampas e inscrições que passam a ocupar as capas e contracapas de cadernos escolares. Essa perspectiva se alinha a argumento apresentado por Eliane Peres e Gizele de Souza, qual seja, de que a "análise da cultura material escolar não pode se esgotar no estudo do próprio artefato, ou seja, é necessário entender que os significados não estão nos objetos apenas, mas nas condutas, valores e sentidos que são atribuídos pelos sujeitos que deles fazem uso" (PERES; SOUZA, 2011, p. 55-56).

Assim anunciada, a temática articuladora deste Dossiê "Cultura Material em História(s): artefatos escolares e saberes" reúne estudos apresentados por pesquisadores de diferentes lugares e instituições. Do exterior temos a participação de Inés Dussel (México), de Carlos Manique da Silva (Portugal) e de Anna Ascenzi (Itália). Do Brasil temos Gizele de Souza (UFPR) e Vera Gaspar (UDESC) que também organizam o dossiê, Juarez José Tuchinski dos Anjos (UnB), Heloisa Pimenta Rocha (UNICAMP), Patrícia Coelho da Costa (PUC-Rio) e Ana Chrystina Mignot (UERJ), Eliane Peres e Caroline Braga Michel (ambas da UFPel). Mais do que apresentar uma nominata queremos aqui evidenciar que os estudos dedicados à cultura material escolar se espraiam por diferentes países, instituições e estados brasileiros, o que é indiciário de sua relevância e potência. Tais estudos se articulam a projetos de pesquisa nos quais diferentes aspectos do provimento material escolar são investigados, apoiados num vasto conjunto de acervos e fontes.

Inicia-se o dossiê com o estudo La cultura material de la escolarización: reflexiones en torno a un giro historiográfico, de Inés Dussel, no qual são analisados alguns pressupostos teóricos e metodológicos da virada material na história da educação. A autora debate a respeito das aproximações anteriores sobre a materialidade e espacialidade do escolar e evidencia aspectos como a inscrição dos objetos em trajetórias que lhes dão movimento e em redes de relações entre humanos e não humanos, e a inclusão das relações de sentido, mas também os efeitos da copresença e interação visível e sensível entre os investigadores e os registros do passado. O texto também realiza reflexões sobre o uso das fotografias como fontes históricas.

Em artigo intitulado Negócios Combinados: modos de prover a escola pública primária (em fins do século XIX e início do XX), de Gizele de Souza e Vera Gaspar, a tônica se volta para examinar modos de provimento material que foram se constituindo paralelamente ao projeto de edificação da escola pública primária, em especial em algumas províncias/estados brasileiros como 
os de Santa Catarina e Paraná. As autoras reafirmam a premissa de que o projeto de escolarização de massas necessitou de uma articulação fecunda com setores comerciais, que assumiram a tarefa de produzir o aparato material que sustentaria a edificação de tal projeto de escolarização da infância. Todavia, as pesquisadoras sustentam que concomitantemente a atuação de um grande comércio havia também outras relações firmadas entre compra e venda que envolvia professores, carpinteiros, e etc. Nesse sentido as autoras formulam a tese da existência de negócios combinados traduzidos por modos diversos nos processos de contratação, negociação e provimento material da escola primária no Brasil.

A análise de diversos modelos de carteiras escolares é realizada no artigo Modelos de carteiras escolares propostos pela Direção-Geral de Instrução Pública de Portugal (1877): a referência da Exposição Universal de Viena, por Carlos Manique da Silva. Uma das ideias que o autor defende é a de que a difusão dos mencionados modelos é legitimada na referência à experiência estrangeira, nomeadamente, a um modelo de carteira escolar (sistema de Kunze) apresentado na Exposição Universal de Viena de Áustria (1873). Manique aponta que as exposições universais tem papel relevante na divulgação de certa forma de escolarização. O autor examina a participação de Portugal na Exposição de Viena de Áustria e a atuação da Direção Geral de Instrução Pública no tocante ao mobiliário escolar. O texto percorre por um conjunto de projetos e modelos de carteiras escolares para o ensino primário e normal, e sustenta a perspectiva da carteira escolar constituir-se um dos expoentes do processo de oficialização do aluno.

Na mesma direção temática sobre as carteiras escolares, Juarez dos Anjos, no texto Para uma história da protoindustria escolar no Brasil Império: A Fábrica Röhe \& Irmãos e seus bancos-carteira (1868-1883), formula o conceito de protoindustria para referir-se às primeiras experiências industriais de produção de móveis para a escola do Brasil Imperial. O autor parte da hipótese de que esta se situaria entre a produção artesanal e a industrial de objetos escolares. Para operar com o conceito mencionado, Anjos toma o estudo do caso da Fábrica Röhe \& Irmãos e os bancos-carteira por ela fabricados, entre 1868 e 1883.

Um outro universo explorado diz respeito a catálogos comerciais da Companhia Melhoramentos de São Paulo, empresa editorial que teve importante atuação na produção e comercialização de uma ampla gama de objetos escolares, examinados no artigo de Heloísa Helena Pimenta Rocha intitulado "Indispensáveis em todas as escolas": uma incursão no mundo dos objetos escolares. Com base na análise deste material e na problematização do seu potencial como fontes para o estudo da cultura material escolar, a autora 
procura levantar os artefatos destinados ao trabalho no âmbito das disciplinas que compunham o currículo e às práticas que tinham lugar na escola e, por essa via, capturar indícios da dimensão material da escolarização da infância.

Dos catálogos de São Paulo examinados por Heloísa Rocha, passamos aos catálogos da fábrica de papel Pigna, pesquisa empreendida por Anna Ascenzi, por meio do trabalho As fábricas de papel Pigna e a produção industrial de cadernos escolares (Itália entre os séculos XIX e XX). A autora examina a produção e comercialização de cadernos escolares e toma como escopo de análise o caso da fábrica mencionada, expondo sua trajetória e mudanças ao longo dos anos no cenário econômico e comercial italiano. A documentação manuseada pela pesquisadora permite atestar que esta fábrica ocupava um lugar distinto de outras empresas que operavam no setor, pois esta acompanhou com seus cadernos o processo de alfabetização e de escolarização de massa dos italianos e consolidou a sua produção para a escola no projeto de educação nacional.

O dossiê também contempla livros didáticos, em específico, cartilhas para o ensino da leitura e escrita como parte constitutiva da cultura material escolar. É este o objetivo do artigo de Eliane Peres e Caroline Braga Michel, intitulado Artefatos da cultura material escolar no Rio Grande do Sul: um estudo das Cartilhas Mestra e Samorim. O texto apresenta uma análise comparada da Cartilha Mestra e da Cartilha Samorim - Recreativa e Instructiva, ambas de autoria do professor gaúcho Samorim Gustavo de Andrade, produzidas no contexto da consolidação do governo no Rio Grande do Sul, da constituição do sistema público de ensino e do crescimento de uma "indústria escolar". As autoras indicam que o estudo permitiu evidenciar que a Cartilha Samorim é uma versão ampliada da Cartilha Mestra, contudo as edições apresentaram algumas especificidades.

Já o texto de Patrícia Coelho da Costa e Ana Chrystina Mignot, Entre recomendações, prescrições e interdições: o aparelhamento moderno nas escolas do Distrito Federal (1939-1942), adentra a proposta do rádio e cinema escolar em meio aos debates e iniciativas dos educadores escolanovistas. Para tanto, as autoras privilegiam em sua análise os jornais, atas, legislação e memórias para interpretar as formas de representação e apropriação de objetos escolares que envolveram recomendações, prescrições e interdições. O texto explora a presença do rádio e do cinema nas escolas no período da administração de Pio Borges no Distrito Federal, assim como trata das proposições de cursos para professores tendo em vista um aparelhamento moderno.

O conjunto de textos abarcados neste dossiê representa possibilidades históricas, na acepção dada por Natalie Davis (1986, p. 10), de interpretação dos processos de escolarização da escola e da sua materialidade, mas também 
revelam muitas potencialidades de investigação a partir de fontes, algumas já largamente difundidas como relatórios, artigos de imprensa e legislação e correspondências de governo, porém outras que são mais particulares como modelos impressos de mobília para a instrução primária, catálogos de livros escolares, exemplares de cartilhas, coleção de capas de cadernos escolares e proposições de rádio e cinema escolar. Esses estudos constituem-se em possibilidades interpretativas e se inserem num movimento de investimento que tem sido realizado no campo da História da Educação com vistas a aprofundar e qualificar a pesquisa empírica e o debate teórico acerca da cultura material escolar.

\section{REFERÊNCIAS}

CERCAS, Javier. $A$ velocidade da Luz. Tradução de Sérgio Molina. 2. Ed. São Paulo: Globo, 2018, p. 202.

DAVIS, Natalie Zemon. O retorno de Martin Guerre. Rio de Janeiro: Paz e Terra, 1986. PERES, Eliane; SOUZA, Gizele de. Aspectos teórico-metodológicos da pesquisa sobre cultura material escolar (im)possibilidades de investigação. In: CASTRO, César Augusto (org.). Cultura Material Escolar: a escola e seus artefatos (MA, SP, PR, SC e RS, 18701925). $1^{a}$ Ed. São Luís: EDUFMA; Café \& Lápis, 2011, v. 1, p. 43-68. 